\title{
Parent Involvement in Young Adults' Intercollegiate Athletic Careers: Developmental Considerations and Applied Recommendations
}

\author{
Travis E. Dorsch \\ Utah State University
}

\author{
Katie Lowe \\ Purdue University
}

\author{
Aryn M. Dotterer \\ Purdue University \\ Logan Lyons \\ Utah State University
}

\begin{abstract}
Student-athletes have to balance their sport, academic, and social lives during the transition to college and parent involvement is an integral, but potentially problematic, aspect of this transition. The present study investigated how key parent involvement factors may be associated with positive developmental outcomes in NCAA Division I student-athletes. Student-athlete participants $(N=514)$ were $46 \%$ male, ranged in age from 18 to 25 years $(M=19.76, S D=1.43)$, and were recruited from athletic departments at two NCAA Division I member-institutions. Participants completed online surveys with items assessing their perceptions of parent involvement (support from parents, contact with parents, academic engagement, athletic engagement) and student-athlete development (academic self-efficacy, athletic satisfaction, well-being, individuation). After controlling for individual and family demographic factors, parent academic and athletic engagement positively predicted student-athlete academic self-efficacy and athletic satisfaction; parent athletic engagement negatively predicted student-athlete depressive symptoms; all aspects of parent involvement were strong negative predictors of emotional independence; support from parents and parent academic engagement were strong negative predictors of functional independence; and support from parents was a negative predictor and athletic engagement a strong positive predictor of student-athletes' attainment of adult criteria. The present research enhances understanding of the role parent involvement may play in student-athlete development and thus may inform the creation of evidence-based policy and programming at NCAA Division I member-institutions.
\end{abstract}

Keywords: intercollegiate athletics, parent involvement, student-athlete well-being, student-athlete development

\footnotetext{
Dorsch and Lyons are with the Families in Sport Laboratory, Department of Family, Consumer, and Human Development, Utah State University, Logan, UT. Lowe and Dotterer are with the Department of Human Development and Family Studies, Purdue University, West Lafayette, IN. Address author correspondence to Travis E. Dorsch at Travis.Dorsch@usu.edu.
} 
College student-athletes are a distinctive population of emerging adults who perceive pressure to succeed athletically and academically (Kirk \& Kirk, 1993; Wylleman \& Lavallee, 2004). For instance, researchers have found that college student-athletes from a range of divisions and sports experience academic difficulties due to a lack of time and energy associated with sport involvement (De Knop, Wylleman, Van Houcke, \& Bollaert, 1999). Student-athletes in all divisions are also more likely than nonathletes to engage in risky behaviors such as drug and alcohol abuse (NCAA, 2012) and unprotected sex (Faurie, Pontier, \& Raymond, 2004). Moreover, student-athletes are at greater risk for mental health problems such as social anxiety and depressive symptoms than nonathlete peers (Gill, 2008; Maniar, Chamberlain, \& Moore, 2005; Watson \& Kissinger, 2007).

Although Côté's (1999) developmental model of sport participation highlights the continued, supportive role of parents for athletes during emerging adulthood, a thorough review of the literature reveals no research to date exploring the role of parent involvement in NCAA student-athlete development. Furthermore, while theorists acknowledge the role of parents in college student development (Perna $\&$ Thomas, 2008) and note that the maintenance of connections to parents during emerging adulthood poses challenges for renegotiating parental involvement (Arnett, 2000; 2004), empirical work has not clearly operationalized key parent involvement factors or identified links between parent involvement and student outcomes, especially among NCAA student-athletes. The present study aimed to fill this gap by investigating links between parent involvement (i.e., parental support, contact, academic engagement, and athletic engagement) and a broad spectrum of student-athlete outcomes (i.e., academic self-efficacy, athletic satisfaction, wellbeing, and individuation).

To guide the study, we drew from conceptual frameworks in developmental psychology and sport psychology. Emerging adulthood (Arnett, 2000; 2004) is recognized as a developmental period that links the end of adolescence and the beginning of young adulthood (approximately ages 18-25). The theory of emerging adulthood asserts that delays in the traditional markers of adulthood (e.g., marriage, parenthood) from about 1950-2000 has led to an extension and redefinition of the time in between adolescence and young, which now offers young people the opportunity to explore their life course before making the commitments required by adult roles. Parents thus remain key socialization agents during this developmental stage because youth rely on parents for support as they become autonomous. As such, the process of achieving self-sufficiency happens in relation to parents, whereby emerging adults gradually transition from parental dependence to self-dependence via increasing responsibility for themselves, independence in decision-making, and financial independence (Arnett, 2004; Tanner, 2006). This theory also posits that emerging adults' maintenance of connections to their parents during this transitional developmental period can impose difficulties with renegotiating the quantity and type of parent involvement, as parents and emerging adults strive to develop more of an egalitarian relationship. Thus, the theory of emerging adulthood provides a broad perspective on how parent involvement is linked to student-athlete development.

We also drew from Côté and colleagues' developmental model of sport participation (Côté, 1999; Côté, Baker, \& Abernethy, 2007). This model highlights the roles of significant others (e.g., coaches, parents, peers, and siblings) in assuring healthy and prolonged sport participation. With regard to parents, the model outlines 
how parent involvement develops over three stages of a child's sport career. During the sampling stage (typically ages 6-12) parents introduce children to sport, enroll them in diverse activities, and provide them with necessary resources, equipment, and time for structured and unstructured play. During the specialization stage (typically ages 13-15) adolescents aim to develop and demonstrate mastery in one or two sports while becoming more engaged in structured and competitive activities. Parents become less involved, but provide more financial and emotional support to help children through the challenges associated with more rigorous training and competition. During the investment stage (typically ages 16+), parents of emerging adults who remain in sport generally progress from a leadership role to a supporting role, whereby regular contact and engagement remain salient as the athlete shifts her/his focus to elite-level mastery and performance. As such, the third stage of this model specifically identifies parent involvement as a developmental process that is integral to an athlete's sport participation in the context of intercollegiate athletics.

Through a combined lens of these theories, it is clear parent involvement has a central role in college student-athlete development. In practice, colleges and universities of varying sizes have tried to adapt to the increasing presence of parents in students' lives via large increases in the provision of parent services (Savage \& Petree, 2011). Furthermore, research conducted over the last decade highlights the role of parents in college students' lives, specifically describing parents' involvement behaviors (e.g., frequency of parent-student communication) in a range of higher education contexts (NSSE, 2007; Pryor, Hurtado, Sharkness, \& Korn, 2007; Tierney \& Auerbach, 2005; Wolf, Sax, \& Harper, 2009). Previous research demonstrates differing associations between types of parent involvement and outcomes among non-student-athlete college students. For example, parent support for academic success has been positively associated with college grade point average (GPA) and academic self-efficacy (Cutrona, Cole, Colangelo, Assouline, \& Russell, 1994; Fulton \& Turner, 2008); however, high levels of parental financial support and parent communication have been negatively associated with college GPA (Hamilton, 2013; NSSE, 2007). While this research suggests that different involvement factors may have diverging associations with academic outcomes, research linking parent involvement factors and well-being among the college student population conveys a more consistent message: parental emotional support and communication predict lower levels of depressive symptoms and risky behaviors across a range of college contexts (Pettit, Roberts, Lewinsohn, Seeley, \& Yaroslavsky, 2011; Small, Morgan, Abar, \& Maggs, 2011).

Research investigating associations between parent involvement and college students' individuation (i.e., becoming more autonomous from one's parents) is underdeveloped even though individuation is a core developmental task during this time period (Arnett, 2000; 2004; Chickering \& Reisser, 1993). Emerging data from a recent study by Lowe (2015), which had a prospective longitudinal design with four measurement occasions, also provides evidence for concurrent links between changes in parent involvement and changes in student outcomes across the first year in college. For example, results revealed that increases in parent support giving and parent-student contact over the first year in college were linked to steeper declines in emotional independence among freshmen across the first year in college. Despite the contributions of this body of literature, there remains a lack of a clear conceptual and operational definition of parent involvement in the 
college context. This gap has led to a large discrepancy between parent program development and empirical research (Wartman \& Savage, 2008; Sax \& Wartman, 2010) in the university setting. Importantly, this gap also exists across the literature on parent involvement in intercollegiate athletics, as no research to date has been conducted to identify parental involvement strategies and/or assess links between parent involvement and student-athlete outcomes.

In the sport domain, multiple interventions have been designed for use with intercollegiate athletes (e.g., Making the Jump, Athletes in Transition). Although there is great value in these programs, each is targeted at student-athletes without consideration for the role parents may play in student-athlete development. This is an important gap in the literature, as parent involvement has been linked to both positive and negative developmental outcomes in transitioning, non-NCAA athletes (e.g., Wylleman \& Lavallee, 2004; Wylleman, Vanden Auweele, De Knop, Sloore, \& De Martelaer, 1995; Zaichkowsky, King, \& McCarthy, 2000. Findings across this small body of research indicate parental emotional support, sport-related advice, and respect for athletes' developing autonomy are positively linked to athletic performance and feelings of success (Würth, 2001; Wylleman, De Knop, \& Van Kerckhoven, 2000). However, given the lack of an operational definition of parent involvement in the context of intercollegiate athletics, and the mixed findings regarding the impact of parent involvement on athlete outcomes, research is warranted to operationalize parent involvement and assess its links with student-athlete outcomes in the context of intercollegiate athletics. In the absence of such knowledge, the development of effective intervention strategies to promote positive parenting and adaptive developmental outcomes in NCAA student-athletes will remain challenging.

The overarching goal of the present research was to provide evidentiary support for key parent involvement factors that are associated with NCAA student-athlete development at the Division I level. Grounded in developmental and sport theoretical frameworks (Arnett, 2000; 2004; Côté, 1999) and supported by an emerging body of literature documenting associations between parent involvement and a range of college student outcomes (e.g., Cutrona et al., 1994; Lowe, 2015; Small et al., 2011), we hypothesized that support from parents, contact with parents, and parent academic and athletic engagement would be associated with student-athlete academic self-efficacy, athletic satisfaction, well-being, and individuation.

\section{Method}

\section{Institutions}

The first institution is an NCAA Division I university located in the intermountain west and maintains an enrollment of 27,812 students. Of these, 302 student-athletes matriculated at the time of the present research. Over the past decade, studentathlete graduation rates have increased from $74 \%$ to $87 \%(M=81.7 \%)$ and 1519 student-athletes have been named academic all conference. These accomplishments are supported by a number of university initiatives designed to enhance studentathlete success (e.g., tutoring and mentoring, preenrollment counseling, priority registration, and life skills programming). In the same 10 -year period, varsity athletic teams have won 25 conference championships and had 35 student-athletes named 
to all-American teams. The second institution is an NCAA Division I university located in the Midwest and maintains an enrollment of 36,616 students. Of these, 499 were student-athletes at the time of the present research. Over the past decade, student-athlete graduation rates have increased from $77 \%$ to $82 \%(M=79.6 \%)$ and 1,444 student-athletes have been named academic all conference. These accomplishments are supported by a number of university initiatives designed to enhance student-athlete success (e.g., tutoring and mentoring, priority registration, and an Academic Success Center on campus). In the same 10-year period, varsity teams/ individuals won 15 conference championships and 12 national championships, while seven student-athletes received all-American honors.

\section{Participants}

Participants were 514 student-athletes from athletic departments at two NCAA Division I member-institutions. In total, 237 males and 275 females participated ( 2 declined to answer) and ranged in age from 18 to 25 years $(M=19.76, S D=1.43)$. Participants identified as freshmen $(n=147)$, sophomores $(n=140)$, juniors $(n=118)$, and seniors $(n=108)$ (1 declined to answer). The sample was comprised of student-athletes who identified as White or Caucasian $(n=401 ; 78 \%)$, Black or African-American $(n=$ $58 ; 11 \%)$, and Asian $(n=19 ; 4 \%)$. Twenty student-athletes $(4 \%)$ identified as "More than one race", 12 student-athletes $(2 \%)$ identified as "Other", and one student-athlete (1\%) reported their race as "Unknown." Three student-athletes declined to report their race. Parents of the student-athlete participants represented a primarily educated cohort of individuals with 410 mothers $(80 \%)$ and 342 fathers $(67 \%)$ having earned at least a bachelor's degree, as reported by their children.

\section{Procedures}

Subsequent to approval by institutional review boards at both universities, the respective athletic departments provided contact information for all current student-athletes (i.e., names and emails). The second and fourth authors met with student-athletes on all athletic teams at both universities. Subsequent to these meetings, student-athletes were sent an e-mail with an embedded link to an 84-item, online survey, which remained active for six weeks postdistribution. Reminder emails were sent at the second and fourth weeks of data collection. Completing the online survey took approximately $15 \mathrm{~min}$, and at the conclusion of the research 10 student-athletes from each university who completed at least $75 \%$ of the online survey were randomly selected as $\$ 50$ gift card winners.

\section{Parent Involvement Measures}

Support From Parents. Student-athlete perceptions of parent support were measured using six items from a modified version of the Social Support Resources index (Fingerman, Miller, Birditt, \& Zarit, 2009; Fingerman, Pitzer, Chan, Birditt, Franks, \& Zarit, 2010). Student-athletes reported how often parents provided six types of support: Emotional, practical, socializing, advice, financial, and discussion about daily events $(\alpha=.82)$. Items were rated on a Likert scale that ranged from 1 (Not at All) to 7 (Daily). Mean scores were created, such that higher scores indicated higher levels of parent support. 
Contact With Parents. Six items were used to assess student-athlete reports of the frequency of parent-student communication via the following six modes of communication: in-person, e-mail, phone, texting, social media, and video chatting (Hofer, 2008; Wolf, Sax, \& Harper, 2009). Items were rated on a Likert scale that ranged from 1 (Not at All) to 7 (Daily). The internal consistency of scores was low $(\alpha=.53)$; however, because it represented a total sum score for communication frequency, regardless of the mode of communication, it was retained.

Academic Engagement. Student-athlete perceptions of parent academic engagement were measured using four items from the University of California Undergraduate Experience Study (UCUES; Wolf et al., 2009). An example item was "My parents and I discuss what I am learning in class," and items were rated on a Likert scale that ranged from 1 (Strongly Disagree) to 5 (Strongly Agree). Mean scores were created, such that higher scores indicated higher levels of parental academic engagement $(\alpha=.75)$.

Athletic Engagement. Student-athlete perceptions of parent athletic engagement were assessed using an adapted version of the 7-item Perceptions of Parents Scale (Robbins, 1994; Niemiec, Lynch, Vansteenkiste, Bernstein, Deci, \& Ryan, 2006). An example item was "My parents allow me to decide things for myself in my sport career," and items were rated on a Likert scale that ranged from 1 (Not at All True) to 5 (Very True). Mean scores were created, such that higher scores indicated higher levels of parental athletic engagement $(\alpha=.93)$.

\section{Student-Athlete Outcome Measures}

Academic Self-Efficacy. Student-athlete perceptions of academic self-efficacy were measured with five items from the Academic Efficacy subscale of the Patterns of Adaptive Learning Scales (Midgley, Maehr, Hruda, Anderman, Anderman, Freeman, Gheen, Kaplan, Kumar, Middleton, Nelson, Roeser, \& Urdan (2000). Items assessed student-athletes' beliefs that they have the abilities and tools to be academically successful. An example item was "I'm certain I can master the skills taught in my classes this year," and responses were scored on a Likert scale that ranged from 1 (Not at All True) to 5 (Very True). Mean scores were created, such that higher scores indicated higher levels of academic self-efficacy $(\alpha=.93)$.

Athletic Satisfaction. Student-athlete perceptions of sport satisfaction were measured using the 6-item Competition Satisfaction Scale (Lochbaum \& Roberts, 1993). Athletic satisfaction is conceptualized as a two-dimensional construct consisting of personal and ability satisfaction. An example item that tapped personal sport satisfaction was, "I know that I've done my best," and an example item that tapped ability satisfaction was, "I believe I showed everyone my superior ability." Items were rated on a Likert scale that ranged from 1 (Strongly Disagree) to 6 (Strongly Agree). Mean scores were created, such that higher scores indicated higher levels of athletic satisfaction $(\alpha=.83)$.

Well-Being. The short version of the Center for Epidemiological Studies-Depressive symptoms Scale (CES-D; Kohout, Berkman, Evans, \& Cornoni-Huntley, 1993) was used to assess how often student-athletes experienced depressive symptoms (e.g., sadness, restless sleep) over the past week. Student-athletes 
responded to 11 items via a Likert scale that ranged from 0 (Rarely or None of the Time [less than 1 day]) to 3 (Most or All of the Time [5-7 days]). Some items were reverse scored so that total summed scores (possible scores ranged from 0 to 33) represented higher levels of depressive symptoms $(\alpha=.83)$. In addition, six items based on questions from the Monitoring the Future Study (Bachman, Johnston, O'Malley, \& Schulenberg, 1996) and the National Longitudinal Study of Adolescent Health (Add Health; Udry, 1998) were used to measure how often $(0=$ None to $6=$ Daily $)$ student-athletes engaged in risky behaviors over the past month. Items assessed risky behaviors across three domains: Risky sexual behaviors (e.g., "Had unprotected sexual intercourse"), risky drinking behaviors (e.g., "Were sick to your stomach or threw up after drinking"), and risky drug use behaviors (i.e., "Used other drugs such as heroin, cocaine, crystal meth, \& mushrooms). The internal consistency of scores in the present study was low $(\alpha=.45)$; however, because the current study aimed to explore links between parenting and overall risky behaviors rather than specific dimensions of risky behaviors, we retained this scale as a total sum frequency score.

Individuation. Student-athletes' perceptions of emotional independence were assessed via a 17-item scale (Hoffman, 1984). Emotional independence reflects emerging adults' abilities to be less dependent on their parents' emotional support and approval. An example item was "I feel longing if I am away from my parent(s) too long," and items were rated on a five-point Likert scale that ranged from 1 (Not at All True of Me) to 5 (Very True of Me). All items were reverse scored, such that higher average scores indicated higher levels of emotional independence from parents $(=.92)$. Student-athletes' perceptions of functional independence were assessed via a 13-item scale (Hoffman, 1984). Functional independence reflects emerging adults' abilities to be less dependent on parental assistance for practical support. An example item was "My parent(s) helps me to make my budget," and items were rated on a five-point Likert scale that ranged from 1 (Not at All True of $\mathrm{Me}$ ) to 5 (Very True of $\mathrm{Me}$ ). All items were reverse scored, such that higher average scores indicated higher levels of emotional independence from parents $(\alpha=.91)$.

Student-athletes' perceptions of their attainment of the three primary criteria for adulthood (i.e., accepting responsibility for oneself, engaging in independent decision-making, and assuming financial independence) were included as a final measure of individuation (Arnett 2000; 2004). The traditional response format for this measure is a three-point scale $(1=$ No, $2=$ In Some Respects Yes and in Some Respects No, 3 = Yes); however, this limited range does not facilitate the ability to capture the gradualness of individuation. Thus, we used an extended response format ( 1 = Strongly Disagree to $5=$ Strongly Agree $)$ to enable assessing variability in individuation that has demonstrated adequate levels of internal consistency among college students (Lowe, 2015; $\alpha$ range $=.58-.65$ ). Mean scores were created such that higher scores indicated higher levels of attainment of adult criteria. While our level of internal consistency for this scale was moderately low $(\alpha=.66)$, it is similar to the aforementioned study's alphas, it is higher than previous researchers who have used the traditional response format (Arnett, 2004; Kins \& Beyers, 2010; $\alpha$ range $=.33-.53)$, and it is very close to the acceptable range for social sciences (i.e., $\alpha=$.70; Cronbach, 1990; Nunnaly, 1978). 


\section{Individual and Family Control Variables}

Student-athlete university, sex, race (i.e., American Indian/Alaskan Native, Asian, Black or African American, Caucasian/White, More than One Race, Unknown, or Other), class standing (i.e., freshmen, sophomore, junior, senior, or other), previous achievement scores (i.e., high school GPA [HSGPA]), and the mean of parents' highest level of education $(M=6.69, S D=1.32$; ranging from elementary school to doctorate degree, where a score of 7 indicated a Bachelor's degree) were the demographic control variables. Because $78 \%$ of the sample identified as Caucasian/ White, student-athlete race was transformed into a dichotomous dummy variable $($ Caucasian/White $=0$; Minority $=1)$.

\section{Data Analysis}

As a first step, descriptive statistics of all study variables were assessed. These included correlations, means, standard deviations, ranges, and frequencies. The univariate normality of all study variables was also assessed.

As a second step, group difference tests were conducted to determine if there were significant differences in parent involvement and student-athlete outcomes by categorical demographic control variables (i.e., student-athlete university, sex, race, and class standing). Specifically, independent samples $t$ tests were conducted to assess differences in study variables by student-athlete university, sex, and race. In addition, one-way analysis of variance (ANOVA) was used to test for differences in study variables by student-athlete class standing. Significant main effects were followed-up with Tukey's HSD post hoc analyses to assess pairwise differences among the four levels of class standing.

As a final step, hierarchical multiple linear regression analyses were conducted to test whether support from parents, contact with parents, academic engagement, and athletic engagement predicted student-athlete academic self-efficacy, athletic satisfaction, well-being (i.e., depressive symptoms \& engagement in risky behaviors), and individuation (i.e., emotional independence, functional independence, and attainment of adult criteria), while controlling for key student-athlete and parent demographic variables (i.e., student-athlete university, sex, race, class standing, and parent education level). To preserve parsimony and reduce model saturation, studentathlete class standing (i.e., freshmen-senior level) was mean centered; thus, results from all models referred to the "average" class standing. Student-athlete HSGPA was included as a control variable in the models predicting academic self-efficacy. Step 1 included the student-athlete and parent demographic control variables, and step 2 added the four parent involvement variables. Incremental $F$-tests were conducted to assess if the change in $R$-square from step 1 to step 2 was significant. These steps were followed for each student-athlete outcome (i.e., academic self-efficacy, athletic satisfaction, depressive symptoms, risky behaviors, emotional independence, functional independence, and attainment of adult criteria) in separate models.

\section{Results}

\section{Descriptive Statistics of Study Variables}

Univariate statistics for nearly all study variables revealed normal distributions and moderate to high levels of internal consistency. Parent athletic engagement 
had a slightly leptokurtic distribution, but was not skewed, indicating most athletic engagement scores were concentrated toward the high end of the response scale. The distribution for attainment of adult criteria followed the same pattern. Engagement in risky behaviors was both positively skewed and leptokurtic, indicating the distribution of scores was concentrated toward the low end of the response scale. In other words, the majority of student-athletes reported very low levels of engagement in risky behaviors.

Table 1 includes correlations between all study variables, as well as univariate statistics (including normality statistics) for all study variables. Parent support, contact, academic engagement, and athletic engagement were all significantly positively correlated with one another; moreover, the effect sizes were moderate to strong, indicating these four variables collectively represented parent involvement in the lives of student-athletes well. Key bivariate relationships between parent involvement and student-athlete outcomes revealed the following: (a) All four parent involvement variables were positively correlated with student-athletes' reports of athletic satisfaction and strongly negatively correlated with studentathletes' reports of emotional and functional independence; (b) Parent academic engagement was the only parent involvement variable that was significantly correlated with academic self-efficacy; (c) Parent support and academic and athletic engagement were negatively correlated with student-athletes' reports of depressive symptoms; (d) Contact with parents was the only parent involvement variable that was correlated with engagement in risky behaviors at the trend level; and (e) While parent support was negatively correlated with attainment of adult criteria, parent academic and athletic engagement were positively correlated with student-athletes' reports of their attainment of adult criteria.

Frequencies of Parent Involvement and Student-Athlete Outcomes. Generally, student-athletes perceived their parents to be supportive and engaged in their academic and athletic pursuits, without being overinvolved. Indeed, the distributions of parent involvement variables revealed that $31 \%$ of student-athletes reported receiving "weekly" support and 50\% reported engaging in contact with their parents "a few times a month". Almost half (45\%) of the student-athletes "agreed" that their parents were academically engaged, and 56\% "strongly agreed". Conversely, only $8 \%$ of student-athletes reported "daily" support from their parents, only $1 \%$ reported "daily" contact with their parents, and only $1 \%$ "strongly disagreed" that their parents were both academically and athletically engaged in their lives.

Student-athlete reports were further explored in an effort to describe how often parents engaged in specific types of support $(n=6)$ and how often specific modes of communication $(n=6)$ were used. Findings indicate that $50 \%$ of student-athletes received emotional support and advice from their parents multiple times per week. In addition, most student-athletes reported that they either had in-person contact with their parents "once every few months" (26\%) or "a few times a month" $(27 \%)$. Over half the respondents did not engage in any e-mail (53\%), social media (54\%), or video chatting $(54 \%)$ with their parents. Finally, phone and texting emerged as the most popular modes of communication, as $32 \%$ of student-athletes reported chatting on the phone "a few times a week" with their parents and $39 \%$ reported texting "daily" with their parents. 


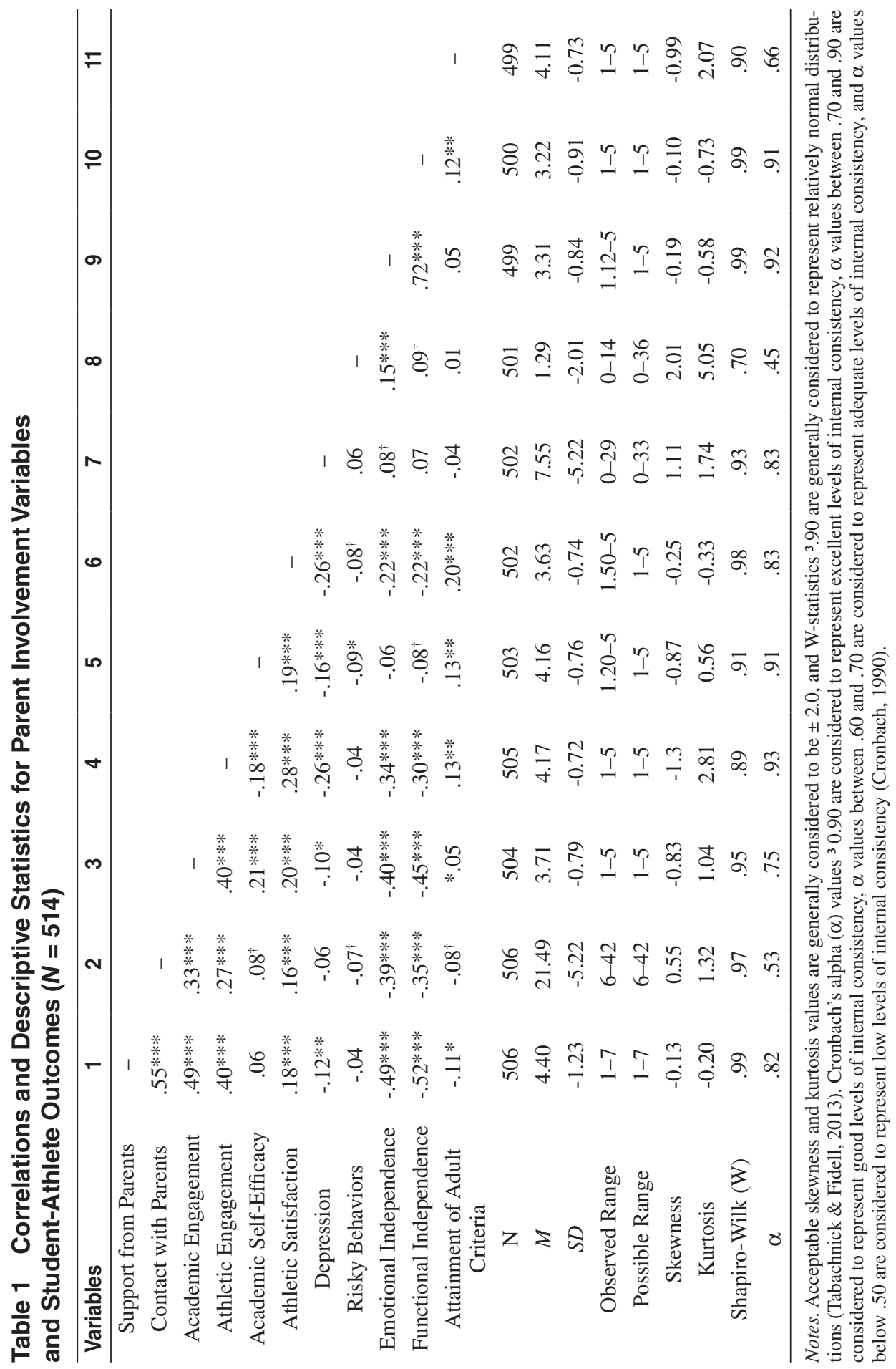


Largely, student-athletes perceived positive developmental outcomes in the context of intercollegiate athletics. The distributions of outcomes revealed that $53 \%$ of student-athletes responded "very true" when asked if they possessed high levels of academic self-efficacy. In addition, $50 \%$ of the student-athletes "agreed" that they were satisfied with their athletic performance. About three-fourths (76\%) of student-athletes reported that they experienced depressive symptoms only "some of the time (1-2 days in the past week)". Importantly, 57\% of the respondents indicated that they did not engage in any risky behaviors, and $40 \%$ reported that they engaged in risky behaviors "once in the past month". Finally, the majority of student-athletes reported that a moderately high level of emotional (40\%) and functional (36\%) independence was "quite a bit true" of them, and $56 \%$ reported that they "strongly agreed" they had attained the criteria necessary for adulthood.

\section{Group Difference Tests}

Student-Athlete University. Support from parents was the only parent involvement variable where significant differences by student-athlete university were found (see Table 2). On average, student-athletes at University A reported higher levels of support from parents than student-athletes at University B. Despite this difference, it is important to note that the average level of support from parents reported by student-athletes from both universities reflected a moderate level of support (i.e., "a few times a month").

Significant differences in student-athlete outcomes by university were found in athletic satisfaction, depressive symptoms, and risky behaviors. On average, student-athletes at University A reported a lower level of athletic satisfaction than student-athletes at University B. In addition, student-athletes at University A reported higher levels of depressive symptoms and engagement in risky behaviors than student-athletes at University B. Despite these differences, it is important to note that the averages reported by student-athletes at both universities reflected moderate levels of athletic satisfaction, low levels of depressive symptoms (i.e., "some of the time [1-2 days in the past week]"), and very low levels of engagement in risky behaviors (i.e., "once in the past month").

Student-Athlete Sex. Contact with parents was the only parent involvement variable where significant differences by student-athlete sex were found (see Table 2). On average, male student-athletes reported a lower level of contact with parents. Despite this difference, it is important to note that the average level of contact with parents reported by both male and female student-athletes reflected a moderate level of contact across all modes of communication (i.e., "a few times a month").

Significant differences in student-athlete outcomes by student-athlete sex were specifically found in depressive symptoms, risky behaviors, and emotional independence. On average, male student-athletes reported fewer depressive symptoms. In addition, male student-athletes reported higher levels of engagement in risky behaviors and emotional independence. Despite these differences, it is important to note that the averages reported by both male and female student-athletes reflected low levels of depressive symptoms (i.e., "some of the time [1-2 days in the past week]"), very low levels of engagement in risky behaviors (i.e., "once in the past month"), and moderately high levels of emotional independence from parents. 


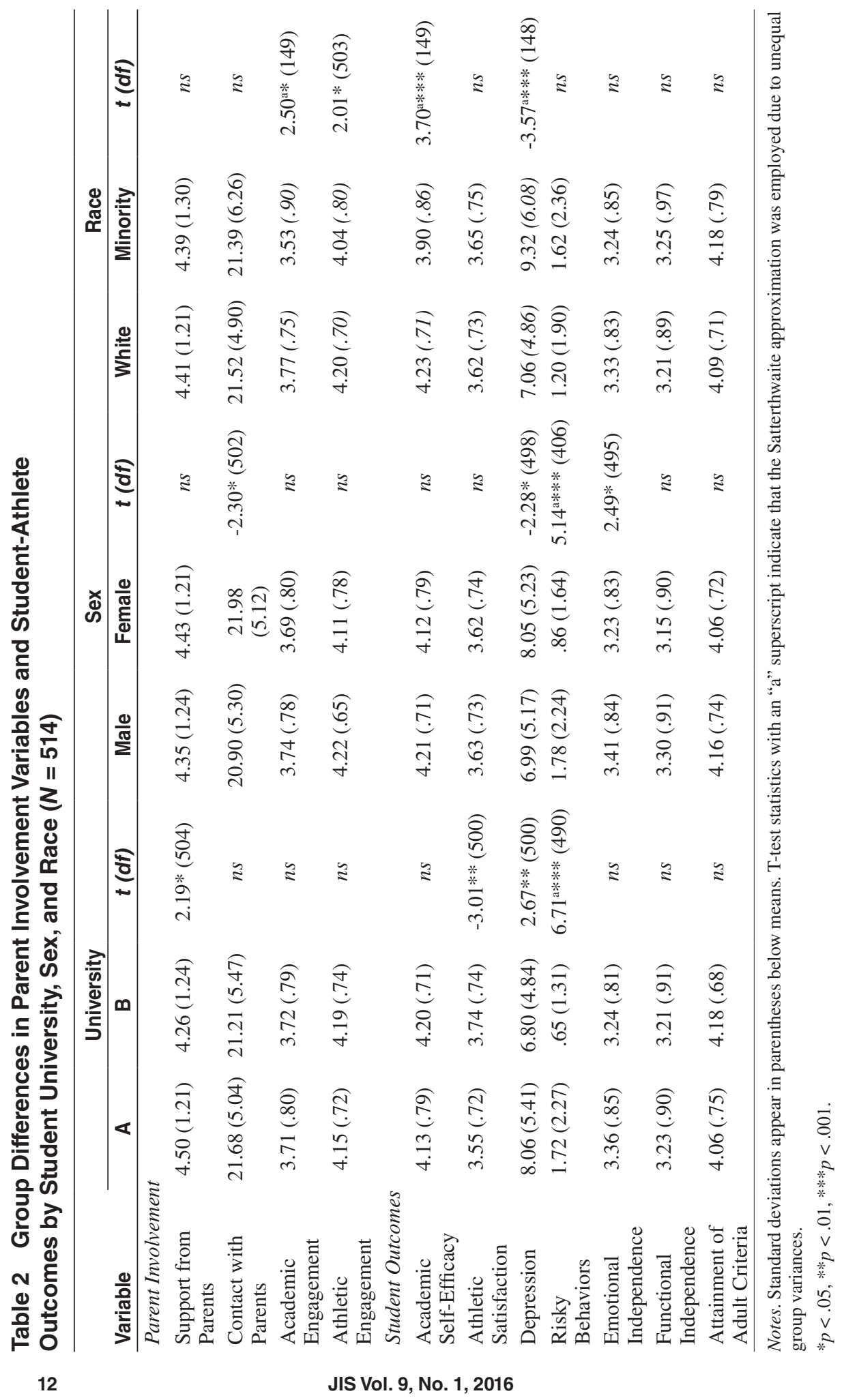


Student-Athlete Race. Significant differences in parent academic engagement and athletic engagement by student-athlete race were found (see Table 2). On average, White student-athletes reported higher levels of parent academic and athletic engagement compared with minority student-athletes. Despite these differences, it is important to note that the averages reported by both White and minority student-athletes reflected moderately high levels of parent academic engagement and very high levels of parent athletic engagement.

Significant differences in student-athlete outcomes by student-athlete race were specifically found in academic self-efficacy and depressive symptoms. On average, White student-athletes reported higher levels of academic self-efficacy and fewer depressive symptoms. Despite these differences, it is important to note that the average level of academic self-efficacy reported by White student-athletes was very high and the average level of academic self-efficacy reported by minority student-athletes was moderately high. Similarly, the average level of depressive symptoms reported by both groups reflected very low levels of depressive symptoms (i.e., "some of the time [1-2 days in the past week]").

Student-Athlete Class Standing. Contact with parents was the only parent involvement variable in which a significant main effect of student-athlete class standing was found, indicating there were differences in the levels of contact reported by freshmen, sophomores, juniors, and seniors (see Table 3). Tukeys's HSD post hoc follow-up analyses revealed freshmen reported higher levels of contact with parents than sophomores. Despite this difference, it is important to note that the average level of contact with parents reported by both freshmen and sophomores reflected a moderate level of contact across all modes of communication (i.e., "a few times a month").

Significant differences in student-athlete outcomes by student-athlete class standing were specifically found in academic self-efficacy, depressive symptoms, and risky behaviors. Tukeys's HSD post hoc follow-up analyses revealed freshmen reported lower levels of academic self-efficacy, more depressive symptoms, and lower levels of engagement in risky behaviors compared with seniors. Freshmen also reported a lower level of risky behaviors compared with juniors. Lastly, sophomores reported a lower level of risky behaviors than juniors. Despite these differences, it is important to note that the average level of academic self-efficacy reported by both freshmen and sophomores was very high. Similarly, the average level of depressive symptoms reported by both freshmen and seniors reflected very low levels of depressive symptoms (i.e., "some of the time [1-2 days in the past week]"). In parallel, levels of risky behaviors reported across all class standings reflected low levels of engagement in risky behaviors (i.e., "once in the past month").

\section{Predicting Student-Athlete Outcomes From Parent Involvement}

Academic Self-Efficacy. The overall model predicting student-athlete academic self-efficacy from the demographic control variables was significant and explained $8 \%$ of the variance in academic self-efficacy (see Table 4). Student-athlete race and class standing were associated with academic self-efficacy, indicating minority 
Table 3 Group Differences in Parent Involvement Variables and Student-Athlete Outcomes by Student Class $(N=514)$

\begin{tabular}{|c|c|c|c|c|c|}
\hline \multirow[b]{2}{*}{ Variable } & \multicolumn{5}{|c|}{ Class } \\
\hline & Freshmen & Sophomores & Juniors & Seniors & $F\left(d f^{n}, d f^{d}\right)$ \\
\hline \multicolumn{6}{|c|}{ Parent Involvement } \\
\hline $\begin{array}{l}\text { Support } \\
\text { from Parents }\end{array}$ & $4.54(1.26)$ & $4.41(1.09)$ & $4.33(1.39)$ & $4.28(1.14)$ & $n s$ \\
\hline $\begin{array}{l}\text { Contact } \\
\text { with Parents }\end{array}$ & $22.50(5.57)^{\mathrm{a}}$ & $20.66(5.06)$ & $21.47(5.01)$ & $21.23(4.99)$ & $3.10 *(3,502)$ \\
\hline $\begin{array}{l}\text { Academic } \\
\text { Engagement }\end{array}$ & $3.78(.77)$ & $3.76(.68)$ & $3.74(.86)$ & $3.53(.85)$ & $n s$ \\
\hline $\begin{array}{l}\text { Athletic } \\
\text { Engagement }\end{array}$ & $4.15(.70)$ & $4.18(.73)$ & $4.16(.69)$ & $4.18(.80)$ & $n s$ \\
\hline \multicolumn{6}{|l|}{ Student Outcomes } \\
\hline $\begin{array}{l}\text { Academic } \\
\text { Self-Efficacy }\end{array}$ & $4.05(.80)^{\mathrm{c}}$ & $4.13(.76)$ & $4.16(.73)$ & $4.33(.69)$ & $2.88 *(3,499)$ \\
\hline $\begin{array}{l}\text { Athletic } \\
\text { Satisfaction }\end{array}$ & $3.66(.70)$ & $3.54(.75)$ & $3.68(.76)$ & $3.62(.74)$ & $n s$ \\
\hline Depression & $8.18(5.51)^{c}$ & $7.57(4.67)$ & $7.92(5.75)$ & $6.28(4.72)$ & $3.00 *(3,498)$ \\
\hline Risky Behaviors & $.80(1.50)^{\mathrm{b}, \mathrm{c}}$ & $1.07(1.75)^{\mathrm{e}}$ & $1.60(2.46)$ & $1.91(2.20)$ & $7.95 * * *(3,497)$ \\
\hline $\begin{array}{l}\text { Emotional } \\
\text { Independence }\end{array}$ & $3.28(.83)$ & $3.28(.82)$ & $3.37(.82)$ & $3.34(.89)$ & $n s$ \\
\hline $\begin{array}{l}\text { Functional } \\
\text { Independence }\end{array}$ & $3.14(.91)$ & $3.16(86)$ & $3.26(.96)$ & $3.36(.89)$ & $n s$ \\
\hline $\begin{array}{l}\text { Attainment of } \\
\text { Adult Criteria }\end{array}$ & $4.03(.74)$ & $4.09(.66)$ & $4.17(.73)$ & $4.16(.79)$ & $n s$ \\
\hline
\end{tabular}

Notes. Standard deviations appear in parentheses beside means. Significant main effects were followed-up with Tukey's HSD post hoc pairwise comparisons. Pairwise comparisons significant at the .05 level are indicated by ${ }^{a}=$ Freshmen vs. Sophomore; ${ }^{b}=$ Freshmen vs. Junior; ${ }^{c}=$ Freshmen vs. Senior; ${ }^{\mathrm{d}}=$ Sophomore vs. Junior; ${ }^{\mathrm{e}}=$ Sophomore vs. Senior; ${ }^{\mathrm{f}}=$ Junior vs. Senior.

${ }^{*} p<.05, * * p<.01, * * * p<.001$.

student-athletes reported lower levels of academic self-efficacy and higher class standing were related to greater academic self-efficacy. Parent education level and HSGPA were also both positively associated with academic self-efficacy, such that a one unit increase in parent education level and HSGPA were associated with a .08 and .15 increase in academic self-efficacy, respectively.

Step 2 added the four parent involvement variables, which explained a significant amount of variance in student-athlete academic self-efficacy above and beyond the demographic control variables. The overall model explained $12 \%$ of variance in student-athlete academic self-efficacy. Parent academic and athletic engagement were both significant predictors of academic self-efficacy. More specifically, for every one-unit increase in parents' academic engagement and athletic 
Table 4 Hierarchical Regression Models Predicting Student-Athlete Academic Self-Efficacy from Parent Involvement Variables $(N=489)$

\begin{tabular}{|c|c|c|c|c|c|c|}
\hline \multirow[b]{3}{*}{ Variable } & \multicolumn{6}{|c|}{ Academic Self-Efficacy } \\
\hline & \multicolumn{3}{|c|}{ Model 1} & \multicolumn{3}{|c|}{ Model 2} \\
\hline & $B$ & SE B & $\beta$ & $B$ & SE B & $\beta$ \\
\hline \multicolumn{7}{|l|}{ Control Variables } \\
\hline Intercept & 3.17 & .31 & & 2.37 & .36 & \\
\hline University $^{\mathrm{a}}$ & .07 & .07 & .04 & .05 & .07 & .03 \\
\hline $\operatorname{Sex}^{\mathrm{b}}$ & -.10 & .07 & -.07 & -.08 & .07 & -.05 \\
\hline Race $^{\mathrm{c}}$ & -.926 & .08 & $-.14 * *$ & -.21 & .08 & $-.12 * *$ \\
\hline Class $^{\mathrm{d}}$ & .09 & .03 & $.13^{* *}$ & .10 & .03 & $.14 * *$ \\
\hline Parent Education Level & .08 & .03 & $.14 * *$ & .06 & .03 & $.11^{*}$ \\
\hline High School GPA & .15 & .07 & $.10 *$ & .13 & .07 & .08 \\
\hline \multicolumn{7}{|l|}{ Parent Involvement } \\
\hline Support from Parents & & & & -.04 & .04 & -.07 \\
\hline Contact with Parents & & & & .01 & .01 & .02 \\
\hline Academic Engagement & & & & .15 & .05 & $.16^{* *}$ \\
\hline Athletic Engagement & & & & .12 & .05 & $.12 *$ \\
\hline$R^{2}$ & & .08 & & & .12 & \\
\hline Overall Model $F$ & & $6.94 * * *$ & & & $6.69 * * *$ & \\
\hline$F$ for change in $R^{2}$ & & & & & $5.88 * * *$ & \\
\hline
\end{tabular}

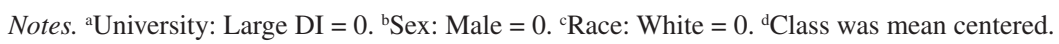

$* p<.05, * * p<.01, * * * p<.001$.

engagement, student-athletes' reports of academic self-efficacy increased by .15 and .12, respectively. Parent academic engagement had the strongest association with academic self-efficacy (see Table 4).

Athletic Satisfaction. The overall model predicting student-athlete athletic satisfaction from the demographic control variables was significant at the trend level, and explained about $2 \%$ of the variance in athletic satisfaction (see Table 5). Step 2 added the four parent involvement variables, and explained a significant amount of variance in student-athlete athletic satisfaction above and beyond the demographic control variables. The overall model explained $13 \%$ of variance in student-athlete athletic satisfaction. Parent academic and athletic engagement were both significant predictors of athletic satisfaction. More specifically, for every one-unit increase in parents' academic engagement and athletic engagement, student-athletes' reports of athletic satisfaction increased by .10 and .23 , respectively. Parent athletic engagement had the strongest association with athletic satisfaction (see Table 5). 
Table 5 Hierarchical Regression Models Predicting Student-Athlete Athletic Satisfaction from Parent Involvement Variables $(N=498)$

\begin{tabular}{|c|c|c|c|c|c|c|}
\hline \multirow[b]{3}{*}{ Variable } & \multicolumn{6}{|c|}{ Athletic Satisfaction } \\
\hline & \multicolumn{3}{|c|}{ Model 1} & \multicolumn{3}{|c|}{ Model 2} \\
\hline & $B$ & SE B & $\beta$ & $B$ & SE B & $\beta$ \\
\hline \multicolumn{7}{|l|}{ Control Variables } \\
\hline Intercept & 3.73 & .18 & & 2.23 & .26 & \\
\hline University $^{\mathrm{a}}$ & .20 & .07 & $.13 * *$ & .20 & .06 & $.13 * *$ \\
\hline $\operatorname{Sex}^{\mathrm{b}}$ & -.03 & .07 & -.02 & -.01 & .06 & -.01 \\
\hline Race $^{c}$ & .04 & .08 & .02 & .09 & .08 & .05 \\
\hline Class $^{\mathrm{d}}$ & .01 & .03 & .01 & .01 & .03 & .02 \\
\hline $\begin{array}{l}\text { Parent Education } \\
\text { Level }\end{array}$ & -.03 & .02 & -.05 & -.04 & .02 & -.08 \\
\hline \multicolumn{7}{|l|}{ Parent Involvement } \\
\hline Support from Parents & & & & .01 & .03 & .01 \\
\hline Contact with Parents & & & & .01 & .01 & .08 \\
\hline $\begin{array}{l}\text { Academic Engage- } \\
\text { ment }\end{array}$ & & & & .10 & .05 & $.11 *$ \\
\hline Athletic Engagement & & & & .23 & .05 & $.22 * * *$ \\
\hline$R^{2}$ & & .02 & & & .13 & \\
\hline Overall Model $F$ & & $2.09^{\dagger}$ & & & $7.85 * * *$ & \\
\hline$F$ for change in $R^{2}$ & & & & & $14.76 * * *$ & \\
\hline
\end{tabular}

Notes. ${ }^{\mathrm{a} U n i v e r s i t y: ~}$ Large DI $=0 .{ }^{\mathrm{b}} \mathrm{Sex}$ : Male $=0 .{ }^{\mathrm{c}}$ Race: White $=0 .{ }^{\mathrm{d}}$ Class was mean centered. ${ }^{\dagger} p<.10,{ }^{*} p<.05, * * p<.01,{ }^{* * *} p<.001$.

Well-Being. The overall model predicting student-athlete depressive symptoms from the demographic control variables was significant, and explained $7 \%$ of the variance in depressive symptoms (see Table 6). Student-athlete university, sex, race, and class standing were associated with academic self-efficacy. These results indicate student-athletes at the smaller of the two universities reported lower levels of depressive symptoms, female student-athletes reported higher levels of depressive symptoms, minority student-athletes reported higher levels of depressive symptoms, and increases in student-athlete class standing were related to lower levels of depressive symptoms.

Step 2 added the four parent involvement variables, and explained a significant amount of variance in student-athlete depressive symptoms above and beyond the demographic control variables. The overall model explained $13 \%$ of variance in student-athlete depressive symptoms. Parent athletic engagement was the only parent involvement variable that was a significant predictor of depressive symptoms. More specifically, for every one-unit increase in parents' athletic engagement, student-athletes' reports of depressive symptoms decreased by 1.56 (see Table 6). 


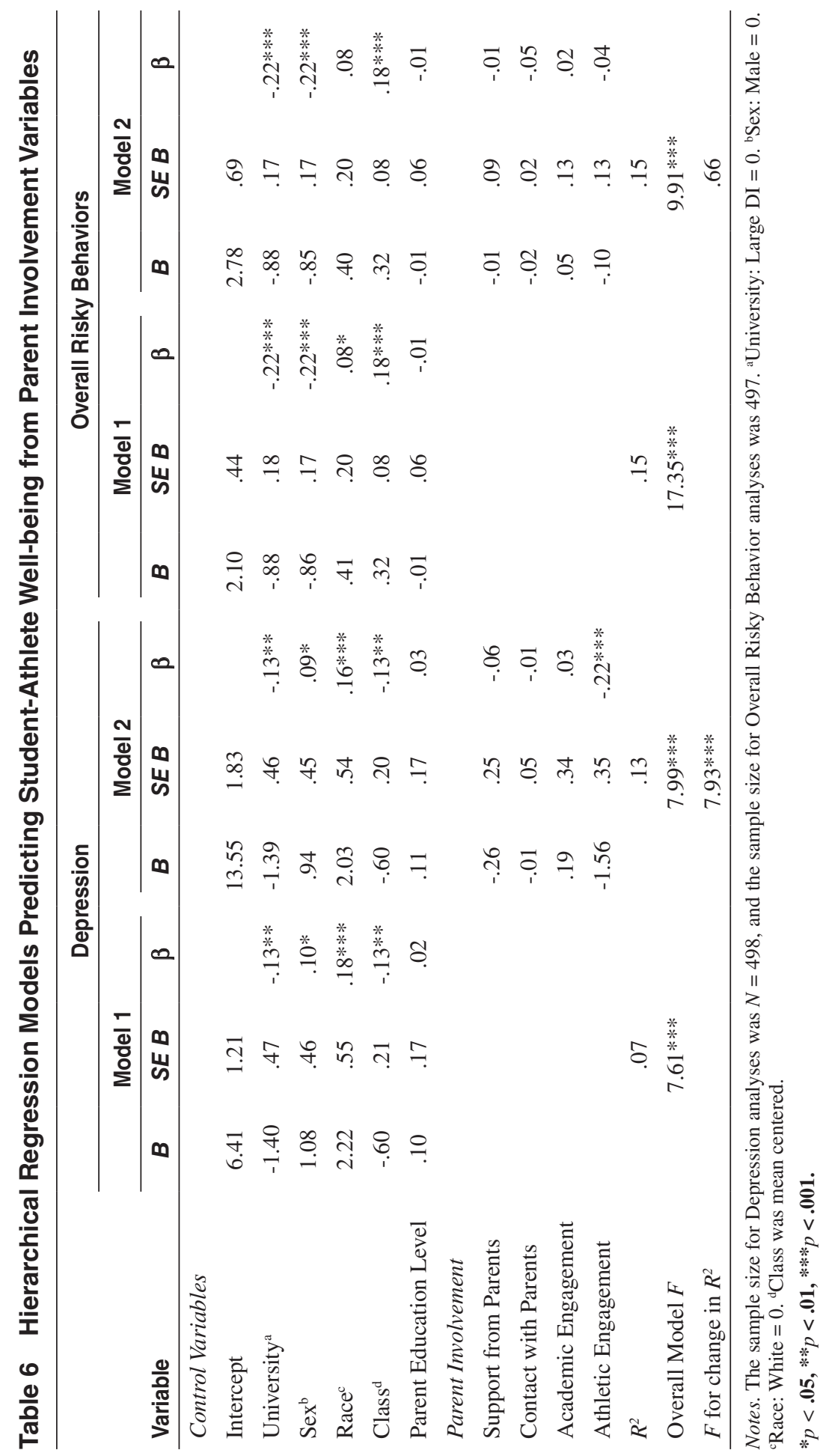


The overall model predicting student-athlete engagement risky behaviors from the demographic control variables was significant and explained $15 \%$ of the variance in risky behaviors (see Table 6). Student-athlete university, sex, race, and class standing were associated with academic self-efficacy. These results indicate student-athletes at the smaller of the two universities and female student-athletes reported lower levels of engaging in risky behaviors, minority student-athletes reported higher levels of risky behaviors, and increases in student-athlete class standing were related to engaging in more risky behaviors. Step 2 added the four parent involvement variables, but did not explain a significant amount of variance in student-athlete depressive symptoms above and beyond the demographic control variables. None of the parent involvement factors were significantly associated with risky behaviors (see Table 6).

Individuation. The overall model predicting student-athlete emotional independence from the demographic control variables was significant at the trend level, and explained about $2 \%$ of the variance in emotional independence (see Table 7 ). Step 2 added the four parent involvement variables, and explained a significant amount of variance in student-athlete emotional independence above and beyond the demographic control variables. The overall model explained $34 \%$ of variance in student-athlete emotional independence. Importantly, all of the parent involvement variables were significant predictors of emotional independence. More specifically, for every one-unit increase in parent support, contact, academic engagement, and athletic engagement, student-athletes' reports of emotional independence decreased by $.19, .02, .21$, and .15 , respectively. Parent support had the strongest association with emotional independence, and explained $7 \%$ of unique variance in emotional independence (see Table 7).

The overall model predicting student-athlete functional independence from student-athlete and parent demographic variables was not significant (see Table 7). Step 2 added the four parent involvement variables, and explained a significant amount of variance in student-athlete emotional independence above and beyond the demographic control variables. The overall model explained $34 \%$ of variance in student-athlete functional independence. Parent support and academic engagement were both significant predictors of functional independence. More specifically, for every one-unit increase in parents' support and academic engagement, studentathletes' reports of functional independence decreased by .26 and .28, respectively. Parent support had the strongest association with functional independence, and explained $12 \%$ of unique variance in functional independence (see Table 7).

The overall model predicting student-athlete's attainment of adult criteria from the student-athlete and parent demographic variables was significant and explained $3 \%$ of the variance in attainment of adult criteria (see Table 7). Student-athlete university and parent education level were significantly associated with attainment of adult criteria. These results indicate student-athletes at the smaller of the two universities reported greater attainment of adult criteria, and that for every one unit increase in parent education level student-athletes reported a .05 decrease in their attainment of adult criteria.

Step 2 added the four parent involvement variables, and explained a significant amount of variance in student-athlete attainment of adult criteria above and beyond the demographic control variables (see Table 7). The overall model explained $7 \%$ of 


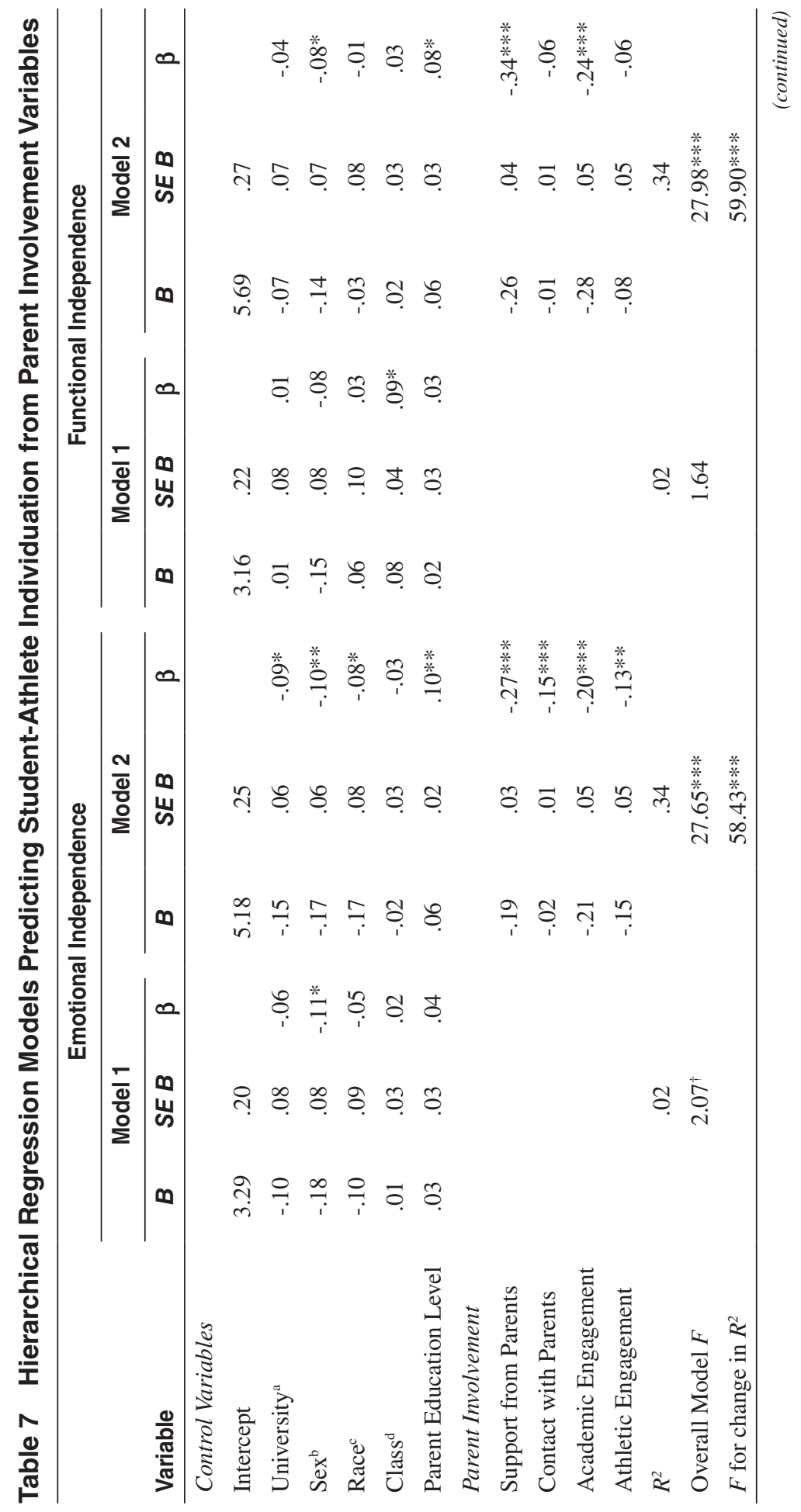




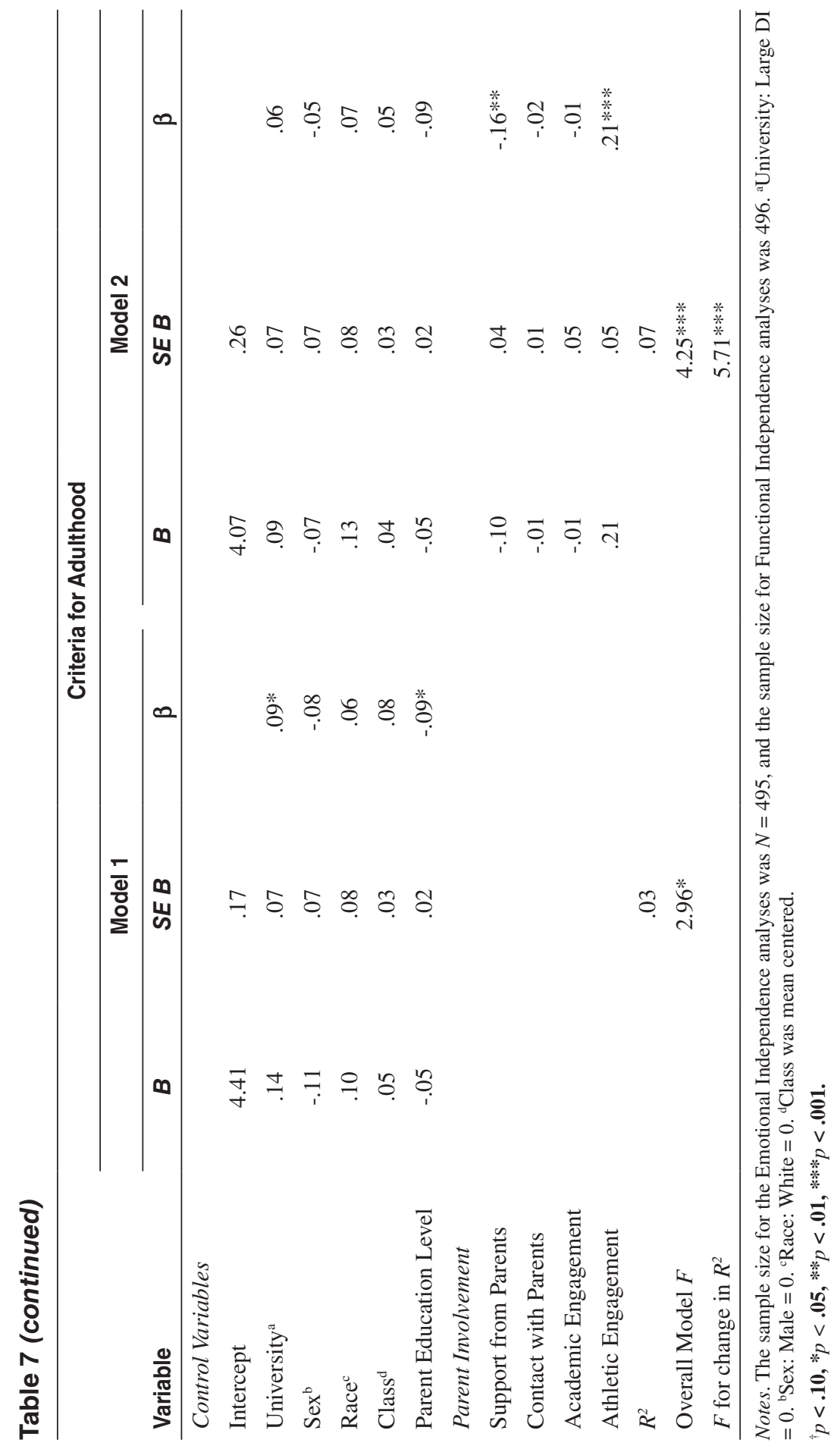


variance in student-athlete attainment of adult criteria. Parent support and athletic engagement were both significant predictors of attainment of adult criteria. More specifically, for every one-unit increase in parents' support, student-athletes' reports of attaining adult criteria decreased by .10. Conversely, for every one-unit increase in parent athletic engagement, student-athletes' reports of attaining adult criteria increased by .21. Parent athletic engagement also had the strongest association with attainment of adult criteria, and explained about $4 \%$ of unique variance in attainment of adult criteria (see Table 7).

\section{Discussion}

In the current study, we sought to address the NCAA's stated mission to promote enhanced student-athlete development, well-being, and mental health by acknowledging the family as a salient source of support for college athletes. Specifically, we investigated the links between parent involvement and student-athlete developmental outcomes. In line with our specific aim, the present research provides evidentiary support for key parent involvement factors that are associated with NCAA student-athlete development. Because this study represents the first attempt to comprehensively assess the role of parents in college student-athlete development, our findings have the potential to inform educational programming for parents of NCAA student-athletes. This programming would complement existing platforms for scholarly and career development of NCAA student-athletes (De Knop et al., 1999; Savage \& Petree, 2011; Sax \& Wartman, 2010; Würth, 2001), and is therefore a necessary step toward shaping parents' involvement behaviors and student-athlete outcomes across the college transition.

In the current study, student-athletes from two NCAA division I memberinstitutions reported on their perceptions of parent involvement and their own developmental outcomes. After controlling for individual and family demographic factors, results indicated that (a) parent academic and athletic engagement positively predicted student-athlete academic self-efficacy and athletic satisfaction, (b) parent athletic engagement negatively predicted student-athlete depressive symptoms, (c) support from parents, contact with parents, parent academic engagement, and parent athletic engagement were strong negative predictors of emotional independence, (d) support from parents and parent academic engagement were strong negative predictors of functional independence, and (e) support from parents was a negative predictor and athletic engagement a strong positive predictor of student-athletes' attainment of adult criteria. These results largely align with previous research on associations between parent involvement factors and outcomes among the general college student population (e.g., Cutrona et al., 1994; Pettit et al., 2011), and validate parents as key agents of support and socialization for emerging adults in college (Arnett, 2000; 2004). Furthermore, findings linking higher levels of parent involvement factors to lower levels of individuation make a critical and novel contribution to this underdeveloped literature. Considering these models explained a significant proportion of variance (up to $34 \%$ ) in individuation, specifically emotional and functional independence, results strongly imply more parent involvement may inhibit the developmental task of becoming autonomous for student-athletes during emerging adulthood. Rather, a moderate amount of involvement (e.g., talking/texting via phone a few times a week, every few weeks ask student-athlete how he/she is 
doing, and let him/her direct conversation's content every few weeks) seems to be more developmentally appropriate for promoting individuation, especially among student-athletes.

Our results also extend Côté and colleagues' (Côté, 1999; Côté et al., 2007) developmental model of sport participation by offering insights into emerging adults' perceptions of parental involvement strategies during the investment stage of elite sport participation. Our results identify parent academic and athletic engagement as strategies that facilitate athletic satisfaction during the investment stage. In other words, the present findings suggest parents who, for example, occasionally talk with their student-athlete about what they're learning in their classes without focusing too much on GPA (i.e., academic engagement strategy) and help their student-athlete develop strategies to effectively deal with sport-related problems (i.e., athletic engagement strategy) tend to have student-athletes who report higher levels of athletic satisfaction. In sum, our results linking parent involvement factors and student-athlete outcomes provide an impetus for future scholarship on the involvement strategies of parents of NCAA student-athletes by more clearly identifying empirically testable involvement behaviors of parents as they aim to facilitate positive developmental outcomes among student-athletes.

Our long-term goal is to offer a mechanism for campus-level programming for parents of NCAA student-athletes that promotes enhanced student-athlete development, well-being, and mental health. This research is an important step toward fulfilling this goal as it informs the strategies that can be implemented to improve the NCAA's efforts to enhance the student-athlete experience. We have used these and other data to create the first versions of an evidence-based manual for NCAA administrators (Dorsch, Lowe, Dotterer, Lyons, \& Barker, 2015a) and a guide for parents of NCAA student-athletes (Dorsch, Lowe, Dotterer, Lyons, \& Barker, 2015b). These products hold the potential to enhance the strategies employed by campus-level administrators and coaches as they aim to improve student-athlete well-being and mental health and are offered to help guide universities' implementation of parent educational programming within the context of intercollegiate athletics. Parent programming for the general student population has become almost ubiquitous across institutions of higher education in America (Savage \& Petree, 2011). Considering that a recent review of these programs found very few were empirically grounded or conducted any research to determine if parent participation in educational programming was related to student outcomes (Savage \& Petree, 2013), our research and evidence-based manuals reflect a constructive step forward to informing the design of parent programming by athletic administrators and student-affairs professionals for both student-athletes and the general student population.

Despite the strengths of this research and the outputs produced, the current study is not without limitations. First, our data only represent the perspectives of a cross-section of student-athletes at the NCAA Division I level. To address this gap, future researchers should design and execute longitudinal studies to provide evidence of parent involvement and its relationship to student-athlete development across the NCAA Division I, II, and III levels. Such research could provide insights into how parent involvement and student-athlete outcomes are linked across the college years, clarifying directionality of involvement-development links and whether those effects are similar or different across the different NCAA Divisions. Second, the voice of parents has yet to be recognized in the Parent Guide and the 
Administrator Manual. To address this missing perspective, researchers should conduct surveys and in-depth interviews with parents of NCAA student-athletes. Such work would allow researchers to synthesize parent experiences with the present research targeting student-athletes, and would facilitate insights into potential reporter discrepancies between parents and students on involvement and studentathlete outcomes. This future research would importantly reduce the monoreporter bias that is present in the current study, and also give a voice to parents as a key perspective in future revisions of the Parent Guide and Administrator Manual. Lastly, although the present research addressed the role of parent involvement in student-athlete development, it is important to acknowledge that larger forces such as television networks, the NCAA, and professional sport franchises shape the culture and experiences of communities, universities, athletic departments, teams, and athletes (Beyer \& Hannah, 2000; Clotfelter, 2011; Comeaux, 2015; Duderstadt, 2000; Noll, 2004; Toma, 2003). For example, the NCAA supports commercial policies that shape athletic department operations and that may or may not be aligned with the mission and academic values of a college or university (Southall, Nagel, Amis, \& Southall, 2008). Future work could adopt an ecological approach (Bronfenbrenner, 2005) in addressing the independent and collective impact of these systems on student-athlete well-being. Such studies would provide a more holistic, and perhaps nuanced depiction of parental involvement and it exists in the lives of NCAA student-athletes.

While this research only included student-athletes from two NCAA Division I member-institutions, it meaningfully contributes to the knowledge base of parent involvement in the context of intercollegiate athletics. Specifically, the present research provides novel evidence for how different types of parent involvement factors may contribute to student-athlete academic self-efficacy, athletic satisfaction, well-being, and individuation. Our findings build on existing work examining associations between parenting and student outcomes during the college transition (e.g., Fulton \& Turner, 2008; NSSE, 2007; Pettit et al., 2011), affirm the importance of offering parents' strategies for enhancing their involvement in a way that is appropriate for the developmental stage of emerging adulthood and the context of intercollegiate athletics, and offer future directions for researchers and practitioners wishing to enhance parent involvement in the context of NCAA athletics.

\section{Acknowledgments}

Research for this project was conducted with the support of the National Collegiate Athletic Association. Any opinions, findings and conclusions are those of the authors and do not necessarily reflect the views of the NCAA. We thank the NCAA student-athletes who took part in the research.

\section{References}

Arnett, J.J. (2000). Emerging adulthood: A theory of development from the late teens through the twenties. The American Psychologist, 55, 469-480. PubMed doi:10.1037/0003066X.55.5.469

Arnett, J.J. (2004). Emerging adulthood: The winding road from the late teens through the twenties. New York, NY: Oxford University Press. 
Bachman, J.G., Johnston, L.D., O’Malley, P., \& Schulenberg, J. (1996). Transition in drug use during late adolescence and young adulthood. In J.A. Graber, J. Brooks-Gunn, \& A.C. Peterson (Eds.), Transitions through adolescence: Interpersonal domains and context (pp. 111-140). Mahwah, NJ: Erlbaum.

Beyer, J.M., \& Hannah, D.R. (2000). The cultural significance of athletics in US higher education. Journal of Sport Management, 14, 105-132.

Bronfenbrenner, U. (2005). Making human beings human: Bioecological perspectives on human development. Thousand Oaks, CA: Sage.

Chickering, A.W., \& Reisser, L. (1993). Education and identity. San Francisco, CA: JosseyBass.

Clotfelter, C.T. (2011). Big-time sports in American universities. Boston, MA: Cambridge University Press. doi:10.1017/CBO9780511976902

Comeaux, E. (2015). Introduction to Intercollegiate Athletics. Baltimore, MD: Johns Hopkins University Press.

Côté, J. (1999). The influence of the family in the development of talent in sport. The Sport Psychologist, 13, 395-417.

Côté, J., Baker, J., \& Abernethy, B. (2007). Practice and play in the development of sport expertise. In R. Eklund \& G. Tenenbaum (Eds.), Handbook of Sport Psychology (3rd ed., pp. 184-202). Hoboken, NJ: Wiley.

Cronbach, L. J. (1990). Essentials of psychological testing (5th ed.). New York, NY: Harper $\&$ Row.

Cutrona, C.E., Cole, V., Colangelo, N., Assouline, S.G., \& Russel, D.W. (1994). Perceived parental social support and academic achievement: An attachment theory perspective. Journal of Personality and Social Psychology, 2, 369-378. PubMed doi:10.1037/00223514.66.2.369

De Knop, P., Wylleman, P., Van Houcke, J., \& Bollaert, L. (1999). Sports management - A European approach to the management of the combination of academics and elitelevel sport. In S. Bailey (Ed.), Perspectives - The interdisciplinary series of Physical Education and Sport Science. Vol. 1. School sport and competition (pp. 49-62). Oxford: Meyer \& Meyer Sport.

Dorsch, T. E., Lowe, K, Dotterer, A. M., Lyons, L., \& Barker, A. (2015a). Administrator manual: Best practices for improving parent involvement in intercollegiate athletics. Logan, UT: Utah State University. Retrieved from: http://www.usufamiliesinsportlab. com/education.html

Dorsch, T. E., Lowe, K, \& Dotterer, A. M. (2015b). Parent guide: Evidence-based strategies for parenting the college student-athlete. Logan, UT: Utah State University. Retrieved from: http://www.usufamiliesinsportlab.com/education.html

Duderstadt, J.J. (2000). A University for the 21st Century. Ann Arbor, MI: University of Michigan Press. doi:10.3998/mpub.16836

Faurie, C., Pontier, D., \& Raymond, M. (2004). Student athletes claim to have more sexual partners than other students. Evolution and Human Behavior, 25, 1-8. doi:10.1016/ S1090-5138(03)00064-3

Fingerman, K., Miller, L., Birditt, K., \& Zarit, S. (2009). Giving to the good and the needy: Parental support of grown children. Journal of Marriage and the Family, 71, 1220-1233. PubMed doi:10.1111/j.1741-3737.2009.00665.x

Fingerman, K.L., Pitzer, L.M., Chan, W., Birditt, K., Franks, M.M., \& Zarit, S. (2010). Who gets what and why? Help middle-aged adults provide to parents and grown children. The Journals of Gerontology. Series B, Psychological Sciences and Social Sciences, 66B, 87-98. PubMed doi:10.1093/geronb/gbq009

Fulton, E., \& Turner, L.A. (2008). Students' academic motivation: Relations with parental warmth, autonomy granting, and supervision. Educational Psychology, 28, 521-534. doi:10.1080/01443410701846119 
Gill, E.L. (2008). Mental health in college athletics: It's time for social work to get in the game. Social Work, 53, 85-88. PubMed doi:10.1093/sw/53.1.85

Hamilton, L.T. (2013). More is more or more is less? Parental financial investments during college. American Sociological Review, 78, 70-95. doi:10.1177/0003122412472680

Hofer, B.K. (2008). The electronic tether: Parental regulation, self-regulation, and the role of technology in college transitions. Journal of the First-Year Experience \& Students in Transition, 20, 9-24.

Hoffman, J.A. (1984). Psychological separation of late adolescents from their parents. Journal of Counseling Psychology, 31, 170-178. doi:10.1037/0022-0167.31.2.170

Kirk, W., \& Kirk, S. (1993). Student athletes: Shattering the myths \& sharing the realities. Alexandria, VA: ACA Press.

Kins, E., \& Beyers, W. (2010). Failure to launch, failure to achieve criteria for adulthood. Journal of Adolescent Research, 25, 743-777. doi:10.1177/0743558410371126

Kohout, F.J., Berkman, L.F., Evans, D.A., \& Cornoni-Huntley, J. (1993). Two shorter forms of the CES-D depression symptoms index. Journal of Aging and Health, 5, 179-193. PubMed doi:10.1177/089826439300500202

Lochbaum, M.R., \& Roberts, G.C. (1993). Goal orientations and perceptions of the sport experience. Journal of Sport \& Exercise Psychology, 15, 160-171.

Lowe, K.E. (2015). Parental Involvement during the college transition: Trajectories and associations with academic success, well-being, and individuation (Unpublished doctoral dissertation). Purdue University, West Lafayette, IN.

Maniar, S., Chamberlain, R., \& Moore, N. (2005). Suicide risk is real for student-athletes. The NCAA News. Retrieved from http://www.ncaa.org.

Midgley, C., Maehr, M. L., Hruda, L. Z., Anderman, E., Anderman, L., Freeman, K. E., Gheen, M., Kaplan, A., Kumar, R., Middleton, M. J., Nelson, J., Roeser, R., \& Urdan, T., (2000). Manual for the patterns of adaptive learning scales. Ann Arbor, MI: University of Michigan.

National Collegiate Athletic Association (NCAA). (2012). National study of substance use trends among NCAA college student-athletes. Indianapolis, IN: NCAA.

National Survey of Student Engagement (NSSE). (2007). Experiences that matter: Enhancing student learning and success. Bloomington, IN: Indiana University Center for Postsecondary Research.

Niemiec, C.P., Lynch, M.F., Vansteenkiste, M., Bernstein, J., Deci, E.L., \& Ryan, R.M. (2006). The antecedents and consequences of autonomous self-regulation for college: A self-determination theory perspective on socialization. Journal of Adolescence, 29, 761-775. PubMed doi:10.1016/j.adolescence.2005.11.009

Noll, R.G. (2004). The organization of sports leagues. Oxford Review of Economic Policy, 19, 530-551. doi:10.1093/oxrep/19.4.530

Nunnally, J. C. (1978). Psychometric theory (2nd ed.). New York, NY: McGraw-Hill.

Perna, L.W., \& Thomas, S.L. (2008). Theoretical perspectives on student success: Understanding the contributions of the disciplines. ASHE Higher Education Report, 34, 1-87.

Pettit, J.W., Roberts, R.E., Lewinsohn, P.M., Seeley, J.R., \& Yaroslavsky, I. (2011). Developmental relations between perceived social support and depressive symptoms through emerging adulthood: Blood is thicker than water. Journal of Family Psychology, 25, 127-136. PubMed doi:10.1037/a0022320

Pryor, J.H., Hurtado, S., Sharkness, J., \& Korn, W.S. (2007). The American freshman: National norms for fall 2007. Los Angeles, CA: Higher Education Research Institute, UCLA.

Robbins, R.J. (1994). An assessment of perceptions of parental autonomy support and control: Child and parent correlates. Unpublished Doctoral Dissertation, Department of Psychology, University of Rochester.

Savage, M., \& Petree, C. (2011). National survey of college and university parent programs: Survey conducted Spring 2011. Retrieved from University of Minnesota, Parent Program Web site: http://www1.umn.edu/parent/about/survey-reports/ 
Savage, M., \& Petree, C. (2013). National survey of college and university parent programs: Survey conducted Spring 2011. Retrieved from University of Minnesota, Parent Program Web site: http://www1.umn.edu/parent/about/survey-reports/

Sax, L.J., \& Wartman, K.L. (2010). Studying the impact of parental involvement on college student development: A review and agenda for research. In J.C. Smart (Ed.), Higher education: Handbook of theory and research (pp. 219-255). doi:10.1007/978-90-481-8598-6_6

Small, M., Morgan, N., Abar, C., \& Maggs, J. (2011). Protective effects of parent-college student communication during the first semester of college. Journal of American College Health, 59, 547-555. PubMed doi:10.1080/07448481.2010.528099

Southall, R.M., Nagel, M.S., Amis, J., \& Southall, C. (2008). A method to March Madness: Institutional logics and the 2006 National Collegiate Athletic Association Division I men's basketball tournament. Journal of Sport Management, 22, 677-700.

Tabachnick, B. G., \& Fidell, L. S. (2013). Using multivariate statistics (6th ed.). New York, NY: Pearson.

Tanner, J. L. (2006). Recentering in emerging adulthood: A critical turning point in lifespan human development. In J. J. Arnett \& J. L. Tanner (Eds.) Emerging adults in America: Coming of Age in the 21 st Century. Washington DC: American Psychiatric Association.

Tierney, W., \& Auerbach, S. (2005). Toward developing an untapped resource: The role of families in college preparation. In W.G. Tierney, Z.B. Corwin, \& J.E. Colyar (Eds.), Preparing for college: Nine elements of effective outreach (pp. 29-48). Albany, NY: State University of New York Press.

Toma, J.D. (2003). Football U.: Spectator sports in the life of the American university. Ann Arbor, MI: University of Michigan Press. doi:10.3998/mpub.16594

Udry, J.R. (1998). The National Longitudinal Study of Adolescent Health (Add Health), Waves I \& II, 1994-1996 (Data Sets 48-50, 98, A1-A3, Kelley, M. S. \& Peterson J. L.) [machine-readable data file and documentation]. Chapel Hill, NC: Carolina Population Center, University of North Carolina at Chapel Hill (Producer). Los Altos, CA: Sociometrics Corporation, American Family Data Archive (Producer \& Distributor).

Wartman, K.L., \& Savage, M. (2008). Parental involvement in higher education: Understanding the relationship among students, parents, and the institution. ASHE Higher Education Report, 33, 1-125.

Watson, J.C., \& Kissinger, D.B. (2007). Athletic participation and wellness: Implications for counseling college student-athletes. Journal of College Counseling, 10, 153-162. doi:10.1002/j.2161-1882.2007.tb00015.x

Wolf, D.S., Sax, L.J., \& Harper, C.E. (2009). Parental engagement and contact in the academic lives of college students. NASPA Journal, 46, 325-358.

Würth, S. (2001). Parental influences on career development. In A. Papaioannou, M.Goudas, \& Y. Theodorakis (Eds.), Proceedings of the 10th World Congress of Sport Psychology (Vol. 3, pp. 21-23). Thessaloniki, Greece: Christodoulidi.

Wylleman, P., De Knop, P., \& Van Kerckhoven, C. (2000). The development of the athlete family as perceived by talented swimmers and their parents. Paper presented at the annual conference for the Association for Applied Sport Psychology (AASP), Nashville, TN.

Wylleman, P., \& Lavallee, D. (2004). A developmental perspective on transitions faced by athletes. In M. Weiss (Ed.), Developmental sport and exercise psychology: A lifespan perspective (pp. 507-527). Morgantown, WV: Fitness Information Technology.

Wylleman, P., Vanden Auweele, Y., De Knop, P., Sloore, H., \& De Martelaer, K. (1995). Elite young athletes, parents and coaches: Relationships in competitive sports. In F. J. Ring (Ed.), The 1st Bath Sports Medicine Conference (pp. 124-133). Bath, United Kingdom: University of Bath - Centre for Continuing Education.

Zaichkowsky, L., King, E., \& McCarthy, J. (2000). The end of an era: The case of forced transition involving Boston University football. In D. Lavallee \& P. Wylleman (Eds.), Career transitions in sport: International perspectives (pp. 195-205). Morgantown, WV: FIT Information Technology. 